\title{
Mobilidade e rendimento escolar dos estudantes de ensino médio em Natal (RN, Brasil)
}

\author{
Mobility and educational performance among high school students in Natal \\ (RN, Brazil)
}

William de Mendonça Lima $a^{[0]}$, Flavio Henrique Miranda de Araujo Freire ${ }^{[b]}$, Ricardo Ojima ${ }^{[b]}$

[a] Universidade Estadual de Campinas (UNICAMP), Núcleo de Estudos de População "Elza Berquó” (NEPO), Campinas, SP, Brasil

[b] Universidade Federal do Rio Grande do Norte (UFRN), Programa de Pós-Graduação em Demografia (UFRN), Natal, RN, Brasil

\section{Resumo}

Pouco explorado pela literatura, os deslocamentos diários casa-escola refletem uma incoerência espacial entre a distribuição da população em idade escolar e os estabelecimentos de ensino de educação básica (nível médio) em Natal, RN. Neste trabalho exploraremos o perfil dos comutadores (estudantes) a partir de um recorte político-administrativo intramunicipal. Dessa forma foi possível captar os fluxos diários de estudantes entre os bairros do município de Natal. Para isso, utilizamos o conceito de espaço de vida como embasamento teórico e o banco de dados do Censo Escolar 2012. Assim, relacionando as informações referentes à localidade de residência e de estudos dos alunos, verificou-se a relação entre o deslocamento para estudo e o desempenho escolar medido através do indicador de distorção idade-série em um modelo de regressão logística. Entre os resultados encontrados identificou-se que a chance de um aluno ter um bom rendimento escolar não está relacionada com a proximidade de sua residência da escola. Nesse sentido, a dinâmica da população em termos de distribuição escolar e de alunos pode representar aspectos importantes para a gestão urbana e a oferta de serviços educacionais, sobretudo em um contexto no qual as tendências demográficas apontam para uma redução expressiva da população em idade escolar nos próximos anos.

Palavras-chave: Mobilidade espacial da população. Comutação. Rendimento escolar.

\section{Abstract}

Little explored in literature, the daily home-school traveling reflects a spatial incoherence between the distribution of the school age population and basic education schools (secondary level) in Natal, Brazil. In this paper, we explore the profile of the commuters (students) from an intra-municipal political and administrative perspective. Thus, we were able to capture the daily flows of students among Natal neighborhoods. For this, we use the concept of living space as theoretical foundation and the school census database in 2012. Thus, the correlation between the place of residence and student studies showed a relationship between the traveling to school and school performance, measured by age-grade distortion in a logistic regression model. We identified

WML: Doutorando em Demografia no Núcleo de Estudos de População “Elza Berquó” (NEPO-UNICAMP), e-mail:lima_william@ymail.com FHMAF: Doutor em Demografia, e-mail: fhfreire@gmail.com

RO: Doutor em Demografia, e-mail: ricardo.ojima@gmail.com 
that the chance for a student to have a good academic performance is not associated to the proximity of his home to school. In this sense, the dynamics of the population in terms of school distribution and students may represent important aspects of urban management and the provision of educational services, particularly in a context where demographic trends point to a significant reduction in school-age population in the next years.

Keywords: Spatial population mobility. Commuting. Academic achievement.

\section{Introdução}

O deslocamento diário de estudantes é uma modalidade da mobilidade espacial da população ainda pouco explorada no Brasil. A maioria dos estudos consideram os deslocamentos para fins de trabalho, principalmente em recortes espaciais intermunicipais em contextos metropolitanos. No entanto, ao se debruçar sobre essa categoria de comutadores ${ }^{1}$ é possível conhecer alguns aspectos peculiares desse fenômeno, tais como: a incoerência entre a oferta e a demanda de ensino, os custos e riscos envolvidos nesse processo de mobilidade, o esgarçamento do espaço de vida dos indivíduos e a relação dos deslocamentos com o seu rendimento escolar (Keserú, 2013; Marique et al., 2013; Pereira, 2006; Marandola, 2006).

Além dessas características, outro aspecto relevante do artigo é o critério geográfico utilizado para analisar esse fenômeno. Isto é, o limite espacial intramunicipal dos deslocamentos que favorece apreender os fluxos diários de estudantes da educação pública de nível médio entre os bairros do município de Natal, RN. Nesse município, assim como em outros, em maior ou menor grau, verifica-se uma assimetria espacial entre oferta e demanda de vagas escolares, pois as escolas que disponibilizam maior número de vagas não estão localizadas sempre nos bairros que concentram o maior contingente populacional em idade escolar. Isso produz um desacoplamento entre o hábitat e as localidades de ensino, obrigando os estudantes a um fluxo diário de deslocamentos.

São poucos os estudos que analisam os efeitos da alocação de serviços educacionais no território da cidade sobre o desempenho escolar. De fato, também

\footnotetext{
${ }^{1}$ No âmbito deste artigo, é o termo derivado da expressão commuting (comutação), que indica um processo de mobilidade diário da população analisado nos limites do bairro. Diferentemente de mobilidade pendular que se refere a deslocamentos que ultrapassam os limites entre os municípios.
}

são raros os estudos no Brasil que abordem o tema dos deslocamentos populacionais por motivo de estudo. Por um lado, trata-se de uma decorrência da relativa escassez de dados que permitam analisar deslocamentos populacionais segundo a tipologia da motivação. E, além disso, a redução das taxas de natalidade no Brasil é um fenômeno relativamente recente e a oferta de serviços educacionais nas idades mais jovens pouco tinha a ver com a otimização dos recursos, pois era raro que alguma escola apresentasse vagas ociosas.

A partir do banco de dados do Censo Escolar 2012 (INEP, 2013), foi possível relacionar as variáveis referentes ao bairro de residência do aluno e ao bairro de localização da escola em que ele estuda. Observou-se que quase metade (46\%) dos estudantes da Região Administrativa (R.A.) Oeste frequentavam escolas fora da sua R.A. de residência, 32\% frequentavam escolas localizadas no mesmo bairro em que residiam e a menor parcela desses estudantes (22\%) frequentava escolas em outros bairros mas na mesma R.A. em que moravam.

Esse quadro de desconexão entre hábitat e unidade de ensino têm se delineado entre os estudantes de ensino médio da educação básica das escolas estaduais da capital potiguar. Nesse contexto emerge a seguinte pergunta: Os deslocamentos diários podem comprometer o seu rendimento escolar? ${ }^{2}$ Assim, o objetivo do artigo foi verificar, em caráter exploratório, a relação entre o deslocamento casa-escola e o rendimento escolar, sem a preocupação de estabelecer relações causais. Ou seja, o risco de um estudante estar numa série defasada com relação à sua idade é maior ou menor se ele mora longe de onde estuda? Metodologicamente, o modelo de regressão logística foi utilizado para identificar qual a chance de um aluno ter um bom rendimento diante da sua localização espacial.

\footnotetext{
${ }^{2}$ Para este artigo, esse conceito refere-se ao grau de distorção idade/série (limite de 2 anos) em que o aluno se encontra.
} 


\section{Mobilidade espacial diária de estudantes: uma breve revisão}

O deslocamento espacial dos indivíduos sobre o território tem dado origem ao desenvolvimento de inúmeros estudos acerca do tema. Diversas são as áreas do conhecimento que procuram desenvolver estudos acerca desse fenômeno de caráter social, econômico e espacial. Uma das categorias de análise mais utilizadas são os movimentos pendulares. Em termos conceituais, esses movimentos se caracterizam enquanto "[...] conjunto de deslocamentos que o indivíduo efetua para executar os atos de sua vida cotidiana (trabalho, compras, lazer)" (Branco et al., 2005, p. 122). Outras peculiaridades dessa modalidade de deslocamento dizem respeito a sua frequência, retenção e situação político-administrativa.

Em termos metodológicos são movimentos de curta distância e, geralmente, diários. Devido à forma de coleta desses dados pelo Censo Demográfico (IBGE, 2011) ${ }^{3}$, também se exige que os limites dos municípios sejam ultrapassados pelos indivíduos para que se consolide um movimento pendular (Jardim, 2011). Por essa razão, embora seja uma das fontes mais abrangentes e comparáveis disponíveis, o fenômeno da mobilidade intraurbana não é captado na sua concepção mais ampla e, portanto, limita-se o uso do Censo Demográfico para análises intramunicipais.

Para Branco et al. (2005), com a expansão das cidades e o espraiamento das localidades de trabalho e deslocamentos diários, cresce a desconexão entre a concentração do emprego e a diluição do hábitat é favorecida pelos meios de transporte. Concomitantemente ao desenvolvimento urbano, emerge a seletividade do solo urbano. Isso produz impactos que afetam a forma urbana, repercutindo na sua expansão, sua segregação socioespacial e, consequentemente, na mobilidade espacial da população, principalmente no âmbito das regiões metropolitanas (Cunha, 2011).

Todavia, é importante enfatizar que esse fenômeno não se limita somente aos contextos metropolitanos. Desde 2000, alguns municípios localizados fora de Regiões Metropolitanas têm apresentado grande crescimento proporcional em movimentos pendulares (Ojima et al., 2007). Segundo esses autores, com

\footnotetext{
${ }^{3} 0$ Censo Demográfico indaga sobre o município de trabalho e/ou estudo quando esse é diferente daquele em que o indivíduo reside. Dessa forma, o uso dos quesitos censitários se restringe aos movimentos intermunicipais, impossibilitando a análise dos deslocamentos intramunicipais.
}

base nos dados do Censo Demográfico, nas últimas décadas, os municípios de 100 a 500 mil habitantes apresentaram grande crescimento no contingente de população que realiza movimento pendular. Mas aqueles de até 5 mil habitantes foram os que tiveram maior incremento no peso relativo desses deslocamentos em relação à população total. Logo, os deslocamentos diários também mereceriam ser analisados, tanto em contextos não metropolitanos quanto em termos de políticas públicas e de planejamento urbano e regional (Ojima et al., 2007; Ojima \& Marandola, 2012).

A expansão desse fenômeno para além das fronteiras metropolitanas evidencia a difusão de aspectos pertinentes ao distanciamento entre as atividades de trabalho e o lugar de moradia. Posto que a mobilidade pendular "[...] reflete o distanciamento progressivo entre o lugar de moradia e de trabalho, fruto da não coincidência dos padrões de distribuição da população e da atividade econômica social [...]" (Pereira \& Herrero, 2011, p. 115). Além dessas características — origem e destino - dos fluxos populacionais para trabalho é imprescindível apontar a tipologia ocupacional dos indivíduos que estão inseridos nesse processo (Ojima et al., 2014). Sendo assim, uma das categorias analíticas pouco exploradas nos fluxos de movimentos pendulares é a dos estudantes.

De fato, a intensidade dos fluxos de pendularidade intermunicipal para estudo é menor do que os fluxos de pendularidade realizados para trabalho, entretanto isso não significaria dizer que aqueles não existam ou sejam irrelevantes. A limitação metodológica na obtenção de dados específicos sobre essa mobilidade para níveis intramunicipais justificaria que no Brasil ainda não existam muitos estudos que abarquem esse público de comutadores. Contudo, essa assimetria espacial tem despertado o interesse, principalmente quando se considera o impacto que a baixa taxa de natalidade tem em termos do crescimento negativo da população em faixas etárias mais jovens.

Com isso queremos dizer que o decrescimento da população em idade escolar favoreceria a política de universalização do ensino básico, mas sem estudos que analisem a distribuição espacial dos estudantes em paralelo à localização dos equipamentos educacionais essa condição não se materializará em avanço na qualidade da educação. A população nos grupos de idade de 0 a 4 anos até 15 a 19 anos apresentou taxas de crescimento negativas entre 2000 e 2010 , diminuindo a pressão por novas vagas escolares nessas idades. Mas se não se levar em consideração a distribuição espacial dessa população, mesmo em 
um contexto de diminuição de crianças e jovens em idade escolar, poderá haver déficit de vagas escolares.

Keserú (2013), em um estudo realizado em Budapeste, afirma que a disponibilidade de instituições de ensino e vagas oferecidas acontece de forma desigual em relação à demanda de alunos existente em determinadas localidades daquela localidade. Segundo o autor, esse descolamento entre hábitat e local de estudo pode se dar por opção própria do aluno ou seus responsáveis. Isso acontece na busca da excelência do ensino. Nesses casos, os alunos (ou seus responsáveis) procuram por instituições com certa tradição na qualidade do ensino e com bons resultados em sistemas avaliativos.

Uma descrição da falta de opção por uma escola próxima de casa ou, da escolha de escolas consideravelmente distantes do local de residência em função da qualidade de ensino está nos resultados do estudo de Pereira (2006). Essa análise é feita entre alunos da rede pública do ensino médio do Distrito Federal. Ele indica que: "[...] 57\% dos alunos de Brasília possuem escolas perto de suas casas [...]" mas optaram por estudar fora dali, e que "[...] 15\% dos alunos não tinham escola pública de ensino médio perto de casa [...]", logo, buscavam escolas fora da sua área de residência (Pereira, 2006, p. 10).

Esses são alguns motivos que podem explicar a motivação dos deslocamentos diários de estudantes. Esse movimento conecta duas funções geográficas sociais: local de residência e de estudo. Assim, os meios de transportes atuam como agentes intermediários de conexão entre essas duas localidades (Keserú, 2013). Eles trazem consequências diretas em termos financeiros (custos com transporte), ambiental (emissão de poluentes) e de saúde (implica se a distância e o percurso viabilizam o aluno ir até e vir da escola a pé ou de bicicleta).

Em um estudo desenvolvido na Alemanha, Müller et al. (2008, p. 342) apontam para o "[...] benefício econômico das escolas de bairro". Esses autores enfatizam os custos com transportes públicos e particulares, assim como a questão ambiental provocada pela emissão de gases de efeito estufa e outros poluentes. Entretanto, para os autores, um dos fatores que influenciam diretamente no maior deslocamento dos estudantes é a diminuição da população e o saldo migratório negativo da região. Ou seja, o poder público precisaria planejar a distribuição de vagas escolares levando em consideração as mudanças demográficas, pois sem isso os investimentos em educação serão defasados. Logo, os estudantes buscariam por serviços de educação em instituições de ensino distantes da sua residência, muitas vezes em outros bairros ou até mesmo em outros municípios.

Schlossberg et al. (2005) falam da realidade de estudantes da educação básica em Bend, Oregon, Estados Unidos, que também estão inseridos nesse processo de descolamento diário residência-escola. Nesse caso, os alunos deslocam-se em direção aos distritos escolares construídos na franja urbana da cidade, área em que os terrenos são menos caros e há espaço para construir instituições de ensino de grande porte, conforme diretrizes do órgão responsável pela educação do Estado.

Muralidharan \& Prakash (2013) desenvolveram estudos acerca da mobilidade com fins educacionais em sua pesquisa sobre o aumento do número de matrículas de meninas no ensino médio no Estado de Bihar, Índia, após a elaboração de uma política pública desenvolvida pelo governo local. Segundo os autores, a queda no número de matrículas entre as meninas é mais pronunciada entre 14 e 15 anos de idade, momento de transição para o ensino médio. Um impedimento para efetuação da matrícula seria a distância das escolas secundárias.

Diante desse impasse, o governo indiano criou uma alternativa para solucionar esse problema. Desenvolveu um projeto - Chief Minister's Bicycle Program - que oferecia bicicletas para meninas matriculadas no ensino médio. A partir de testes de hipóteses, os autores conseguiram comprovar uma relação significante entre o aumento de matrículas de meninas no ensino médio e o programa desenvolvido pelo governo.

Em estudo de Marique et al. (2013), na Bélgica, considera-se que a probabilidade de locomoção de bicicleta ou a pé para a escola diminui à medida que a distância da viagem aumenta. Além disso, aponta-se para a existência de uma correlação com a segurança de rotas e limitações de tempo da família. Observou-se que houve um crescimento do comportamento de mobilidade para a escola nas últimas décadas. E, associado a isso, ocorreu maior demanda por transportes e consumo de energia (combustível). E que esse consumo de energia nos transportes para se deslocar para escola é fortemente dependente do nível escolar. Ou seja, quanto maior o nível escolar, maior a distância percorrida e o consumo de energia.

Portanto, seria possível afirmar que a distância entre a residência e a escola é condição determinante na vida escolar e que os instrumentos de acesso (os meios de transportes) são importantes recursos 
de conexão entre a residência e escola. Além disso, se há um processo de envelhecimento relativo da população com um crescimento populacional em idades mais avançadas, a etapa do ciclo de vida de uma população deve ser fator importante para entender o deslocamento das pessoas no espaço urbano. Assim, o planejamento urbano e regional poderá ter muito a ganhar se se entender melhor a dinâmica demográfica de uma determinada região.

Estudar em outro bairro ou município diferente daquele em que o jovem reside pode lhe proporcionar aspectos positivos, como a ampliação da rede social e consolidação de novos lugares para o jovem. Porém, por outro lado, isso se limita a alguns ambientes que frequenta no decorrer de suas atividades escolares, já que o trajeto que realiza diariamente dificilmente permitiria uma aproximação adequada com aspectos de filiação aos lugares de passagem. Assim, estudar longe de casa pode se constituir num processo de fragmentação de contextos de filiação e segurança, no qual o indivíduo estaria exposto a maiores dificuldades.

Maiores distâncias entre casa e escola podem envolver o jovem em dois aspectos distintos e contraditórios: ampliar sua rede social e visões de mundo ou aumentar a exposição a fatores de risco e a vulnerabilidade. Desse modo, a partir da análise dos espaços de vida seria possível conectar as análises do espaço urbano com aspectos educacionais. Enfim, considerando-se que nas últimas décadas os deslocamentos para trabalho e/ou estudo estão aumentando em termos de intensidade, proporção e distâncias mesmo em pequenos e médios municípios, torna-se fundamental entender os efeitos do espaço sobre o social (Ojima, 2007).

\section{Comutação de estudantes de ensino médio em Natal e rendimento escolar}

Se os deslocamentos diários entre a residência dos estudantes e a respectiva unidade de ensino têm se tornado a tônica do desenvolvimento social e urbano contemporâneo, entender como a distância casa-escola pode afetar o desempenho escolar é uma questão fundamental. Sobretudo se considerarmos que as baixas taxas de crescimento da população nesses grupos etários tenderiam a favorecer a melhoria das condições de oferta de vagas escolares. Como recorte espacial de análise foi privilegiado o município de Natal (RN) e os estudantes de ensino médio da rede pública.

Conhecer a caracterização da distribuição espacial da população em idade escolar no município é importante do ponto de vista demográfico, pois interfere em várias esferas sociais, dentre elas a educação, visto que o entendimento das questões demográficas pode servir de subsídio para o planejamento educacional (Adarosa \& Szmrecsányi, 1980). A partir da Figura 1,

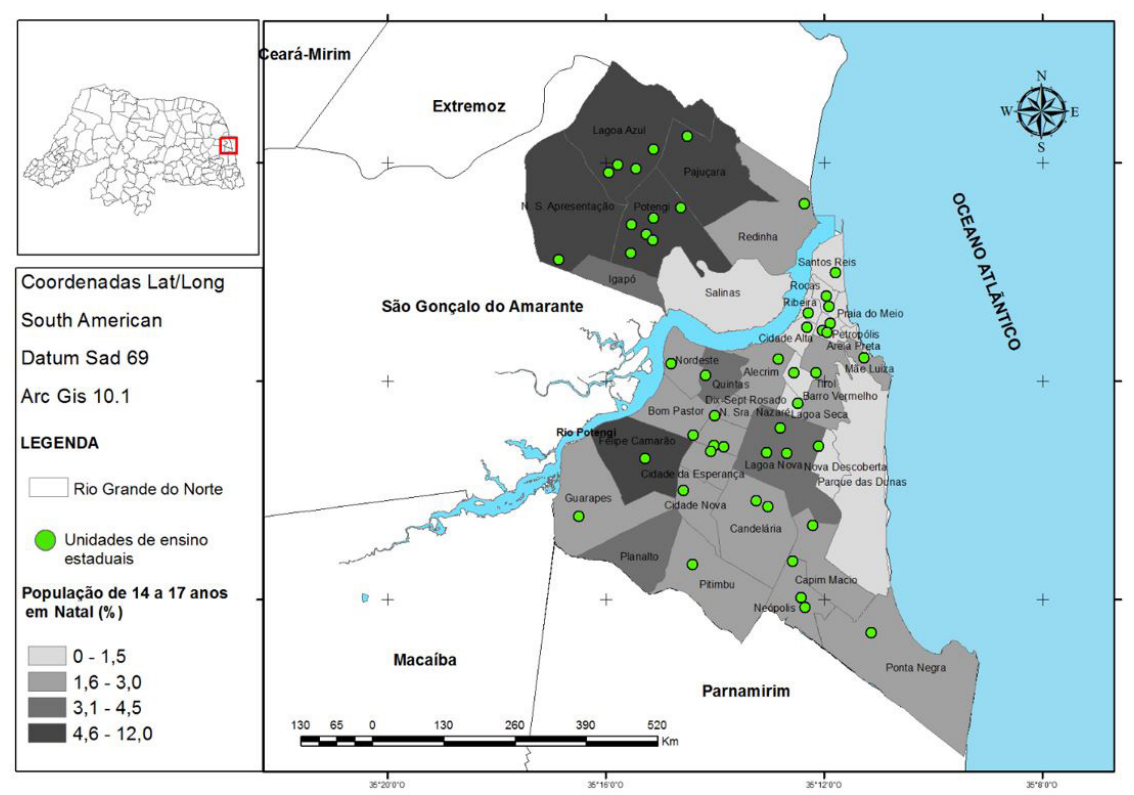

Figura 1 - Distribuiç̦ão espacial da população de 14 a 17 anos e das unidades de ensino em Natal (SEMURB, 2012) Fontes: SEMURB (2012), Censo Escolar de 2012 (INEP, 2013) e Censo Demográfico de 2010 (IBGE, 2011). 
observa-se que bairros como Nossa Senhora da Apresentação, Lagoa Azul, Pajuçara, Potengi e Felipe Camarão concentram entre $4,6 \%$ a $12,0 \%$ do total da população de 14 a 17 anos do município. Isso é, grande parte em idade potencial de frequentar o nível médio da educação básica.

Foram identificadas 48 escolas públicas (estaduais) que oferecem serviço de educação de ensino médio (INEP, 2013). No entanto, essas unidades de ensino não estão distribuídas coerentemente em relação a população em idade de frequentar o nível médio da educação básica. Assim, percebe-se uma assimetria espacial entre oferta e demanda de ensino. Como forma de ilustrar a existência importante de jovens estudando fora de seu bairro, utilizou-se o agrupamento segundo as Regiões Administrativas (RA) para indicar como essa distribuição se dá de maneira diferenciada na cidade.

Através das informações da Figura 2 é possível apreender o processo de desacoplamento entre residência e localidades de estudo em Natal, pois nota-se que apenas na RA Sul é predominante a ocorrência de alunos estudando no mesmo bairro que residem. Logo, fica evidente que em todas as demais RAs existem jornadas de maior distância no deslocamento casa-escola. Na RA Norte, $43 \%$ dos estudantes residem no mesmo bairro em que estudam. Consequentemente, não precisam submeter-se à longos processos de comutação diária e seus desdobramentos. Subentende-se que percorrem distâncias menores até a escola e despendem menos tempo no deslocamento. Porém, mais da metade da população de estudantes dessa RA não se encontra

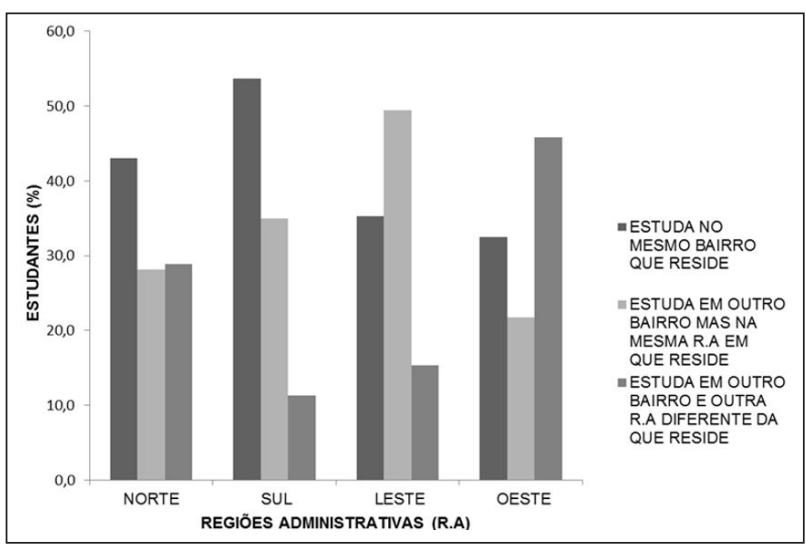

Figura 2 - Mobilidade espacial dos estudantes de ensino médio da rede pública em Natal segundo regiões administrativas (em \%), 2012 Fontes: SEEC (2013); INEP (2013). nessa situação. Ou seja, 28\% e 29\%, respectivamente, estudam em outros bairros, seja na mesma RA ou em bairros de RA diferente daquela em que residem.

A situação da RA Sul é um pouco diferente da RA descrita acima, na qual apenas $11 \%$ de estudantes estudam em RA diferente daquela em que residem. A RA Leste é a que apresenta o maior percentual de alunos que estudam em bairros diferentes daqueles em que residem, mas dentro dos limites da sua RA. Quase a metade (49\%) da sua população de estudantes da rede pública de ensino médio encontra-se nessa situação. Isso revela a capacidade de manter os estudantes em escolas nessa RA, embora em bairros diferentes daqueles em que residem. Além de atrair estudantes de outros bairros que não estão inseridos na RA e até mesmo alunos de outros municípios da Região Metropolitana de Natal, que procuram as unidades de ensino tradicionais que existem nessa RA.

Dentre os estudantes dessa RA, 35\% moram no mesmo bairro em que está localizada sua escola. E uma menor parte desses estudantes (16\%) estuda em RA diferente daquela em que reside. Essas são as principais características espaciais dos estudantes e das escolas da RA Leste. Por último, nesse contexto, cabe destacar as particularidades da RA Oeste, cuja dinâmica espacial dos estudantes diverge muito da de outras RAs, como a Leste e a Sul, principalmente. Quase metade (46\%) dos jovens RA Oeste estudava em escola fora da sua RA de residência. A menor parcela desses estudantes (22\%) estudava em outros bairros, mas na mesma RA que moravam.

\section{Procedimentos metodológicos}

\section{Fontes de dados e modelo estatístico}

A partir das informações apresentadas na Figura 2 foi possível construir um quadro geral sobre a mobilidade espacial dos estudantes de ensino médio entre os bairros e as RAs do município de Natal. Essas informações confirmam a ocorrência de um processo assimétrico de distribuição espacial de estudantes e de equipamentos escolares em Natal. Portanto, o objetivo principal deste estudo foi identificar a existência de alguma relação entre a distância casa-escola e o rendimento escolar dos alunos de ensino médio da rede pública de Natal. 
Fontes de dados

A base de dados utilizada foi o Censo Escolar 2012 realizado pelo INEP e as informações sobre o bairro de residência dos alunos foram obtidas junto à Secretaria Estadual de Educação e Cultura do Rio Grande do Norte (SEEC, 2013). Esses dados estão agregados em bairros. Utilizamos alguns indicadores de desempenho das escolas da página do INEP na internet. 0 Censo Demográfico 2010 também foi utilizado e teve papel importante na aquisição de informações sobre a distribuição espacial da população (na faixa etária de 14 a 17 anos) na cidade de Natal.

\section{Modelo estatístico: regressão logística}

A partir da compilação das informações, utilizou-se o modelo de regressão logística binária, uma ferramenta estatística utilizada para "[...] explicar ou predizer a ocorrência de determinado evento em função de um conjunto de variáveis [...]" (Dias \& Corrar, 2009, p. 282). A escolha metodológica ocorreu em função da variável dependente ser categórica e dicotômica, isto é, a variável dependente assume dois valores, e os resultados só podem estar em um grupo ou em outro, nesse caso, rendimento escolar do aluno (aluno nivelado ou aluno desnivelado, de acordo com a relação entre idade e série em que estava matriculado) (Ribas \& Vieira, 2011).

Neste artigo, a regressão logística é proposta com a função de avaliar a relação entre as variáveis independentes e a variável resposta sobre o rendimento escolar. 0 interesse aqui está em mensurar as relações entre as variáveis, em termos das chances de o aluno estar ou não desnivelado, segundo as características mensuradas nas variáveis independentes incluídas no modelo. Dessa maneira, essas relações são medidas sob critérios de significância estatística, diferentemente de uma análise apenas descritiva dos dados.

De modo geral, a mecânica do método consiste na conversão da variável resposta em razões de chance, que é a razão entre duas probabilidades, em seguida se aplica uma transformação logarítmica (Dias \& Corrar, 2009). A conversão da probabilidade associada a cada observação em razão de chance (odds ratio), que representa a probabilidade de sucesso comparada à de fracasso, é representada da seguinte forma (Equações 1 e 2):
Razãode Chance $=\frac{P(\text { sucesso })}{1-P(\text { sucesso })}$

Em seguida, para construção do modelo, obtém-se o logaritmo natural da razão de chance:

$\ln \left(\frac{P(\text { sucesso })}{1-P(\text { sucesso })}\right)=b_{0}+b_{1} x_{1}+b_{2} x_{2}+\ldots b_{z} x_{z}$

em que $l n$ é o logaritmo natural e $b_{0} ; b_{1} ; b_{2} e b_{z} e x_{1} ; x_{2} e x_{z}$ são, respectivamente, os coeficientes (parâmetros) estimados e as variáveis independentes.

Dessa maneira é possível identificar a probabilidade associada à ocorrência de determinado evento. Considerando-se o conceito de chance, é possível obter a seguinte Equação 3:

$P($ sucesso $)=\frac{e^{\left(b_{0}+b_{1} x_{1}+b_{2} x_{2}+\ldots b_{z} x_{z}\right)}}{1+e^{\left(b_{0}+b_{1} x_{1}+b_{2} x_{2}+\ldots b_{z} x_{2}\right)}}$

Esse é o procedimento que permite calcular a probabilidade relativa à ocorrência de determinado evento.

As variáveis independentes utilizadas no modelo foram: "sexo"; "transporte público" (se utiliza ou não) e "localização" (se (1) mora no mesmo bairro onde estuda; (2) mora em outro bairro, mas na mesma Região Administrativa (RA); (3) mora em outro bairro e outra RA; e (4) mora em outro município. A variável resposta ou dependente, como já foi dito anteriormente, é o "rendimento escolar do aluno" (se ele está nivelado ou não em relação à série escolar em que está matriculado, isto é, a distorção idade-série) ${ }^{4}$. Inicialmente também foram incluídas as variáveis cor/raça e idade. No entanto, a partir da estatística de teste de Wald, elas foram não significantes, por isso retiradas da análise.

Abaixo (Equação 4) segue o modelo ajustado com seus respectivos coeficientes e as variáveis significativas.

$y=-1,28-0,48 x_{1}+0,52 x_{2}-0,15 x_{3}-0,69 x_{4}-0,38 x_{5}$

$y$ Razão de chance rendimento escolar;

${ }^{4}$ A variável distorção idade-série representa o nível de desnivelamento de um aluno em determinada série. De acordo com o que propõe a legislação educacional brasileira, o aluno é considerado desnivelado quando ultrapassa 2 anos da idade indicada para determinada série em que estiver matriculado (INEP, 2015). 
Tabela 1 - Modelo logístico ajustado

\begin{tabular}{lcccccc}
\hline \multicolumn{1}{c}{ Variáveis } & B & S.E & WALD & DF & SIG & EXP(B) \\
\hline Sexo feminino $\left(\mathrm{x}_{1}\right)$ & $-0,48$ & 0,04 & 124,12 & 1 & 0,000 & 0,62 \\
Transporte público $\left(\mathrm{x}_{2}\right)$ & 0,52 & 0,09 & 34,93 & 1 & 0,000 & 1,69 \\
Estuda em outro bairro, na mesma RA $\left(\mathrm{x}_{3}\right)$ & $-0,15$ & 0,05 & 8,13 & 1 & 0,004 & 0,86 \\
Estuda em outra RA $\left(\mathrm{x}_{4}\right)$ & $-0,69$ & 0,06 & 145,55 & 1 & 0,000 & 0,5 \\
Estuda em Natal, mas vem de outro município $\left(\mathrm{x}_{5}\right)$ & $-0,38$ & 0,07 & 30,91 & 1 & 0,000 & 0,69 \\
Constante & $-1,28$ & 0,04 & 1027,79 & 1 & 0,000 & 0,28 \\
\hline
\end{tabular}

Fontes: SEEC (2013) e INEP (2015).

$y=\ln \left[\frac{p(x)}{1-p(x)}\right]$, em que $\mathrm{p}(\mathrm{x})$ é a probabilidade de o aluno estar desnivelado;

$-1,28$ Constante do modelo;

$x_{1}$ Estudantes do sexo 1 (feminino); masculino ficou como categoria base;

$x_{2}$ Não utiliza transporte público; utiliza transporte público ficou como categoria base;

$x_{3}$ Estudantes que estudam em outros bairros, mas na mesma Região Administrativa em que residem; estudantes que estudam no mesmo bairro em que residem ficou como categoria base;

$x_{4}$ Estudantes que estudam em outros bairros e em outra Região Administrativa, diferente daquela em que reside; estudantes que estudam no mesmo bairro em que residem ficou como categoria base;

$x_{5}$ Estudantes que estudam em Natal, mas residem em outros municípios. estudantes que estudam no mesmo bairro em que residem ficou como categoria base.

A escolha do modelo se baseou na deviance que, assintoticamente, tem distribuição qui-quadrado. Segundo Hosmer \& Lemeshow (1989), essa estatística tem o mesmo papel da soma de quadrados dos resíduos na regressão linear, isto é, quanto menor o seu valor, melhor será o modelo. Quanto menor o valor da deviance mais a verossimilhança do modelo ajustado está próxima da verossimilhança do modelo saturado, indicando que aquele estaria predizendo muito bem os valores observados, minimizando os resíduos. 0 modelo ajustado e descrito acima teve p-valor para deviance igual a 0,496 , indicando que o modelo testado prediz valores que não têm diferença significante dos valores observados, ou seja, é um bom modelo.

As variáveis independentes foram incluídas no modelo, mediante análise da deviance e da significância estatística de cada uma delas, verificada através do teste de Wald, conforme resultados da Tabela 1.

\section{Resultados}

A partir desses resultados é possível afirmar que um estudante do sexo feminino tem 0,62 vezes chance de estar desnivelado do que um aluno do sexo masculino. Isso significa dizer que a chance de uma jovem estar desnivelada é 38\% menor do que de um jovem estudante do sexo masculino. Esse resultado mostra que há melhor rendimento escolar das meninas comparativamente aos meninos. Com relação à forma de deslocamento dos estudantes no percurso para escola, a chance de um aluno que não utiliza transporte público estar desnivelado é $69 \%$ maior do que aquele que utiliza esse recurso.

As próximas três razões de chance a serem analisadas no contexto do rendimento escolar (desnivelado) dizem respeito à localização da residência do aluno. Essas variáveis estão classificadas como localização final 2, 3 e 4, significando, respectivamente, que o aluno estuda em outro bairro, mas na mesma RA que reside" (2); "estuda em outro bairro e outra RA, diferente daquela em que reside" (3); e, por último, que o aluno "estuda em Natal, mas reside em outro município fora da capital potiguar" (4). A localização 1 - "estuda no mesmo bairro que reside" - foi utilizada como categoria de referência e, portanto, os resultados das categorias 2, 3 e 4 devem ser comparadas a ela.

Como resultado, a chance de um aluno que estuda em outro bairro mas na mesma RA em que reside estar desnivelado é $14 \%$ menor do que aquele que estuda no mesmo bairro em que reside. Já a chance de um aluno que estuda em outra RA diferente daquela em que reside estar desnivelado é $50 \%$ menor do que aquele 
que estuda no mesmo bairro em que reside. Por último, é importante destacar os resultados referentes àqueles alunos que não residem em Natal, mas estudam nesse município. A sua chance de estar desnivelado é 31\% menor em comparação àquele que estuda no mesmo bairro em que reside no município de Natal.

Diferentemente do que se esperava, os resultados revelaram que morar mais distante da escola não é um aspecto negativo no âmbito do rendimento escolar dos alunos. Observou-se que alunos que moram fora dos limites do bairro onde estudam têm menores chances de desnivelamento do que aqueles que residem e estudam no mesmo bairro. Isso talvez revele a ambivalência da mobilidade, uma vez que ela pode adquirir caráter negativo, comprometendo os mecanismos de proteção do indivíduo. Mas também pode funcionar enquanto um ativo, ampliando as possibilidades de articulação com redes sociais, por exemplo. Ela pode viabilizar acesso a recursos que estão indisponíveis àqueles que estão em um estado de imobilidade. Enfim, "[...] a possibilidade da mobilidade permite que as pessoas busquem recursos fora do lugar, do seu território mais imediato, suprindo carências [...]" (Marandola, 2008, p. 145).

0 que se presume é que além da incoerência entre oferta e demanda para esse nível da educação básica, muitos estudantes procuram escolas melhor conceituadas, independentemente de sua localização. Nesse caso seriam alunos mais jovens (visto que estão nivelados) que se submeteriam a um processo diário de deslocamento.

As Figuras 3 e 4 mostram essa relação. Na Figura 3, a relação é inversa $(r=-0,5196$; $p$-valor $=0,000)$, mostrando que as escolas com maior proporção de

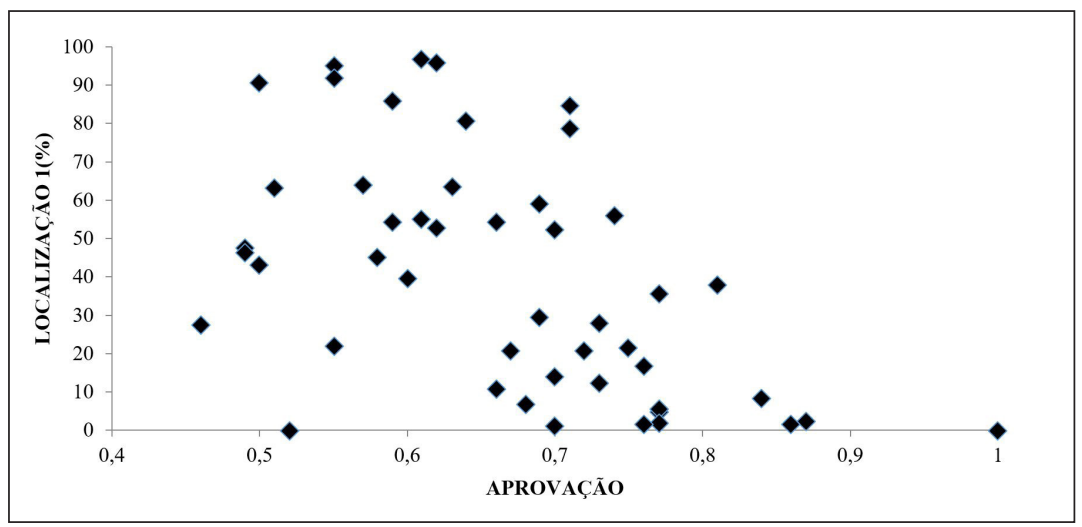

Figura 3 - Relaçã̃o entre a proporção de alunos com aprovação e percentual de alunos que residem no mesmo bairro da escola, para cada uma das escolas estaduais de ensino médio de Natal, 2012

Fontes: SEEC (2013); INEP (2013).

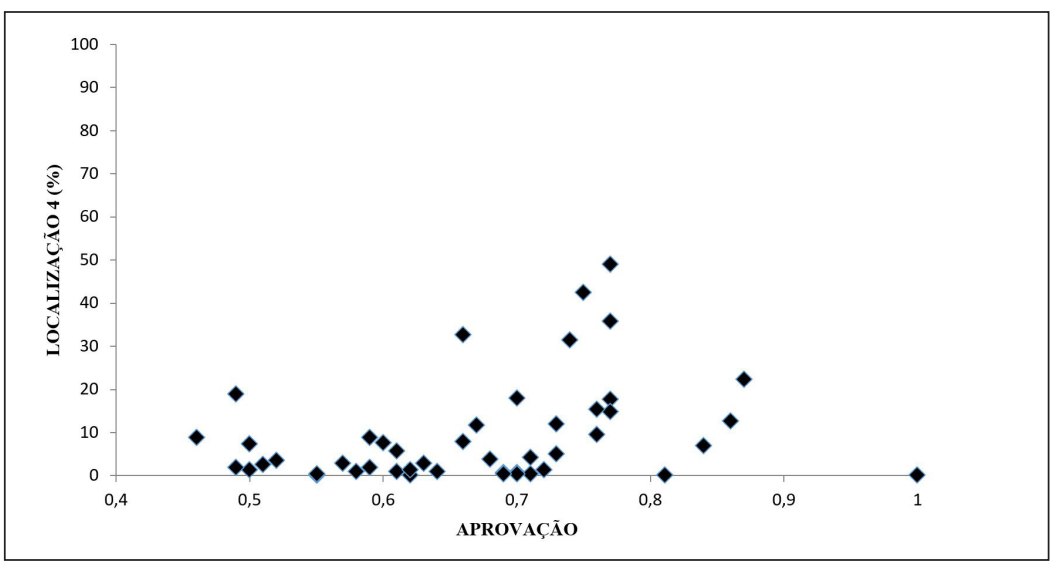

Figura 4 - Relação entre a proporção de alunos com aprovação e percentual de alunos que residem fora do município de Natal, para cada uma das escolas estaduais de ensino médio de Natal, 2012 Fontes: SEEC (2013); INEP (2013). 
alunos aprovados no ensino médio possuem menor percentual de alunos que residem no mesmo bairro. Por outro lado, tomando o outro extremo da variável "localização", que são aqueles estudantes que, apesar de estudarem em escolas de Natal, residem fora do município, a Figura 4 mostra inversão na relação $(r=0,3145$; p-valor $=0,0295)$. Nesse caso, embora a relação seja mais fraca, ainda é significante. As escolas com maior proporção de alunos aprovados são as que apresentam maior percentual de alunos que residem em outro município. Tomando-se a proporção de aprovação como uma proxy de taxa de sucesso, uma medida de qualidade da instituição, ratifica-se a hipótese levantada a partir dos resultados da regressão logística, de que escolas melhores atraem alunos, com os estudantes e suas famílias avaliando as instituições de ensino e buscando aquelas com melhor estrutura.

\section{Considerações finais}

Diante da organização espacial da distribuição das unidades de ensino pública de educação básica (nível médio) e da residência dos estudantes desse ciclo da educação em Natal, RN, foi observado certa incoerência entre oferta e demanda desse serviço entre os bairros desse município. Nas Regiões Administrativas (RA) Norte e Oeste, por exemplo, mais da metade dos estudantes de ensino médio estudavam em escolas de bairros diferentes daqueles em que residiam. Considerando-se que $46 \%$ dos estudantes da segunda RA, além de estudarem em outros bairros diferentes daquele em que residiam, estudavam em outras RA, o que os inseria em fluxos mais longos.

Esses fluxos demonstraram a dinâmica de integração entre os bairros de Natal, RN, além da capacidade de conectar duas funções geográficas sociais: local de residência e de estudos. 0 que demonstrou que esse fenômeno vai além das questões espaciais e pode comprometer os elementos de proteção (comunidade, lugar e família) dos estudantes, impactando negativamente em seu rendimento escolar.

No entanto, os resultados que relacionavam variáveis no âmbito do deslocamento e rendimento escolar forneceram resultados contrários aos que se costuma considerar em termos de planejamento. Ou seja, os resultados demonstram que a distância da escola tem relação positiva com o rendimento escolar dos alunos. Isso mostra o caráter ambivalente da mobilidade, pois tanto pode comprometer os elementos de proteção do indivíduo, expondo-o a riscos, como também pode ter um efeito positivo, funcionando enquanto um ativo de proteção, permitindo-lhe acessar serviços indisponíveis no local de residência. 0 espaço de vida desses alunos com maior mobilidade tende a ser mais ampliado e esse talvez seja, potencialmente, o motivo pelo qual seu rendimento escolar aparentemente se apresenta melhor. Ou seja, como o modelo estatístico utilizado não permite atribuir relações de causa e efeito, não teríamos como saber se são características prévias ao deslocamento para estudo que mais influenciam no seu melhor desempenho em relação àqueles que estudam no seu próprio bairro de residência.

De certa maneira, considerando-se as condições de ensino em algumas escolas públicas em bairros mais segregados, buscar opções de estudo em localidades mais distantes pode ser um distintivo para aqueles que de uma forma ou de outra já possuem alguma rede social de apoio ou características familiares que os incentivem a buscar melhores condições de estudo. Assim, tratar-se-ia de um viés de seleção, pois estudar longe de casa pode ser um reflexo da busca de melhores condições de estudo e a explicação para piores condições de nivelamento entre aqueles que estudam no bairro onde residem, uma consequência da própria dificuldade de se mover.

Pode-se, portanto, concluir que este artigo contribuiu para lançar luz sobre os efeitos da distribuição espacial dos serviços de educação dentro do município. Como discutido, são raros os estudos que tratam dos deslocamentos populacionais como motivo de estudo, tanto intra como intermunicipais, no Brasil. 0 artigo contribui na exploração do uso de dados do Censo Escolar como ferramenta de planejamento urbano e regional, pois diante da carência de estudos nessa direção, mostrou-se uma possibilidade de análise que pode ser mais explorada com resultados importantes.

\section{Referências}

Adarosa, P., \& Szmrecsányi, T. (1980). Demografia e educação. In J. L. F. Santos, M. S. F. Levy, \& T. Szmrecsányi, (Org.), Dinâmica da população: teoria, métodos e técnicas de análise. São Paulo: T.A Queiroz.

Branco, M. L. G. C.; Firkowski, O. L. C. F., \& Moura, R. (2005). Movimento pendular e perspectivas de pesquisas em aglomerados urbanos. São Paulo em Perspectiva, 19(4), 121-133. 
Cunha, J. M. P. (2011). Mobilidade espacial, vulnerabilidade e segregação socioespacial: reflexões a partir do estudo da RM de Campinas, 2007. In Cunha, J. M. P. (Org.), A mobilidade espacial da população: desafios teóricos e metodológicos para o seu estudo. Campinas: Núcleo de Estudos de População - NEPO/Unicamp. p. 117-140.

Dias, J. M., Fo., \& Corrar, L. J. Regressão logística. (2009). In L. J. Corrar, E. Paulo, \& J. M. Dias Fo., (Coords.), Análise multivariada: para cursos de administração, ciências contábeis eeconomia (pp. 280-323). São Paulo: Atlas/Fundação Instituto de Pesquisas Contábeis, Atuariais e Financeiras - FIPECAFI.

Hosmer, D. W., \& Lemeshow, S. (1989). Applied logistic regression. Massachusetts: John Wiley \& Sons.

Instituto Brasileiro de Geografia e Estatística - IBGE. (2011). Censo Demográfico de 2010. Rio de Janeiro: IBGE.

Instituto Nacional de Estudos e Pesquisas Educacionais Anísio Teixeira - INEP. (2013). Censo Escolar da Educação de 2012. Rio de Janeiro: INEP.

Instituto Nacional de Estudos e Pesquisas Educacionais Anísio Teixeira - INEP. (2015). Portal INEP. Recuperado em 10 de janeiro de 2015, de http://portal.inep.gov.br/

Jardim, A. P. (2011). Movimentos pendulares: reflexões sobre mobilidade pendular. In L. A. P. Oliveira, \& A. T. R. Oliveira (Orgs.), Reflexões sobre os deslocamentos populacionais no Brasil (pp. 58-70). Rio de Janeiro: IBGE.

Keserú, I. (2013). Commuting patterns of secondary school students in the funcional urban region of Budapest. Hungarian Geographical Bulletin., 62(2), 197-219.

Marandola, E., Jr. (2006). Mobilidade e Vulnerabilidade nos Espaços de Vida de Campinas. In XV Encontro Nacional de Estudos Populacionais (18-22 de setembro). Caxambú: ABEP.

Marandola, E., Jr. (2008). Habitar em risco: mobilidade e vulnerabilidade na experiência metropolitana (Tese de Doutorado). Instituto de Filosofia e Ciências Humanas, Universidade Estadual de Campinas, Campinas.

Marique, A. F., Dujardin, S., Teller, J., \& Reiter, S. (2013). School commuting: the relationship between energy consumption and urban form. Journal of Transport Geography, 26, 1-11. http://dx.doi.org/10.1016/j.jtrangeo.2012.07.009.

Müller, S., Tscharaktschiew, S., \& Haase, K. (2008). Travelto-school mode choice modelling and patterns of school choice in urban areas. Journal of Transport Geography, 16(5), 342-357.http://dx.doi.org/10.1016/j.jtrangeo.2007.12.004.

Muralidharan, M., \& Prakash, N. (2013). Cycling to School: Increasing Secondary School Enrollment for Girls in India (Discussion Papers Series, No. 7585). Bonn: IZA. 45 p.
Ojima, R. (2007). Análise comparativa da dispersão urbana nas aglomerações urbanas brasileiras: elementos teóricos e metodológicos para o planejamento urbano e ambiental (Tese de Doutorado). Instituto de Filosofia e Ciências Humanas, Universidade Estadual de Campinas, Campinas.

Ojima, R., \& Marandola, E., Jr. (2012). Mobilidade populacional e um novo significado para as cidades: dispersão urbana e reflexiva na dinâmica regional não metropolitana. Revista Brasileira de Estudos Urbanos e Regionais, 14(2), 103-116. [ANPUR] http://dx.doi.org/10.22296/2317-1529.2012v14n2p103.

Ojima, R.; Aguirre, M. A. C.; Silva, B. L. \& Lima, W. M. (2014). Migrações internacionais motivadas por estudo: uma análise sociodemográfica dos estudantes estrangeiros radicados no Brasil. Revista PerCursos, 15(28), 166-189.

Ojima, R.; Silva, R. B. \& Pereira, R. H. M. (2007) A mobilidade pendular na definição das cidades-dormitório: caracterização sociodemográfica e novas territorialidades no contexto da urbanização brasileira. Cadernos PUR/UFRJ, 21,111-132.

Pereira, R. H. M. (2006). Polarização urbana e mobilidade da população: 0 caso dos deslocamentos pendulares na rede pública de ensino médio do Distrito Federal. In $X V$ Encontro Nacional de Estudos Populacionais (18-22 de setembro). Caxambú: ABEP.

Pereira, R. H. M., \& Herrero, V. (2011). Mobilidade pendular: uma proposta teórico-metodológica. In: T. Aidar, \& E. Pelaez. (Orgs.), Estudos demográficos na Argentina e Brasil: resultados de cooperação entre estudantes e docentes da Unicamp e UNC (pp. 106-127). Campinas: SPU/AR, CAPES/BR.

Ribas, J. R., \& Vieira, P. R da C. (2011). Análise Multivariada com o uso do SPSS. Rio de Janeiro: Editora Ciência Moderna Ltda.

Schlossberg, M., Phillips, P. P., Johnson, B., \& Parker, B. (2005). How do they get there? A spatial analysis of a 'sprawl school' in Oregon. Planning Practice and Research, 20(2), 147-162. http://dx.doi.org/10.1080/02697450500414678.

Secretaria de Estado da Educação e da Cultura - SEEC. (2013). Natal - RN: Governo do Estado do Rio Grande do Norte.

Secretaria Municipal de Meio Ambiente e Urbanismo SEMURB. (2012). Anuário Natal: 2011-2012. Natal - RN: Setor de Pesquisa e Estatística - SPE.

Recebido: Jul. 27, 2017

Aprovado: Out. 17, 2017 